\title{
Attribution of the Observed Spring Snowpack Decline in British Columbia to Anthropogenic Climate Change ${ }^{\mathscr{O}}$
}

\author{
MOHAMmAd REZA NAJAFI ${ }^{\mathrm{a}}$ AND FranCIS ZWIERS \\ Pacific Climate Impacts Consortium, University of Victoria, Victoria, British Columbia, Canada \\ NATHAN GiLLETT \\ Canadian Centre for Climate Modelling and Analysis, Environment and Climate Change Canada, Victoria, \\ British Columbia, Canada
}

(Manuscript received 4 March 2016, in final form 15 December 2016)

\begin{abstract}
A detection and attribution analysis on the multidecadal trend in snow water equivalent (SWE) has been conducted in four river basins located in British Columbia (BC). Monthly output from a suite of 10 general circulation models (GCMs) that participated in phase 5 of the Coupled Model Intercomparison Project (CMIP5) is used, including 40 climate simulations with anthropogenic and natural forcing combined (ALL), 40 simulations with natural forcing alone (NAT), and approximately $4200 \mathrm{yr}$ of preindustrial control simulations (CTL). This output was downscaled to $1 / 16^{\circ}$ spatial resolution and daily temporal resolution to drive the Variable Infiltration Capacity hydrologic model (VIC). Observed (manual snow survey) and VICreconstructed SWE, which exhibit declines across $\mathrm{BC}$, are projected onto the multimodel ensemble means of the VIC-simulated SWE based on the responses to different forcings using an optimal fingerprinting approach. Results of the detection and attribution analysis shows that these declines are attributable to the anthropogenic forcing, which is dominated by the effect of increases in greenhouse gas concentration, and that they are not caused by natural forcing due to volcanic activity and solar variability combined. Anthropogenic influence is detected in three of the four basins (Fraser, Columbia, and Campbell Rivers) based on the VIC-reconstructed SWE, and in all basins based on the manual snow survey records. The simulations underestimate the observed snowpack trends in the Columbia River basin, which has the highest mean elevation. Attribution is supported by the detection of human influence on the cold-season temperatures that drive the snowpack reductions. These results are robust to the use of different observed datasets and to the treatment of low-frequency variability effects.
\end{abstract}

\section{Introduction}

Snowpack plays a prominent role in the hydrologic cycle of snow-dominated regions by modulating the timing of peak river flows. Water that is stored seasonally as snow, together with that stored in glaciers, supplies more than one-sixth of the global population

Supplemental information related to this paper is available at the Journals Online website: http://dx.doi.org/10.1175/ JCLI-D-16-0189.s1.

\footnotetext{
${ }^{a}$ Current affiliation: Department of Civil and Environmental Engineering, Western University, London, Ontario, Canada.
}

Corresponding author: Mohammed Reza Najafi, mnajafi7@ uwo.ca
(Barnett et al. 2005). Therefore, it is necessary to quantify the amount of precipitation that falls and accumulates as snow in winter and spring and gradually drains during the high water demand summer and autumn seasons for water resource management and planning. British Columbia, located in western Canada, has many nival and glacial rivers in which the spring snow storage has a major influence on summer streamflow and spring flood (Moore and McKendry 1996).

Warming reduces the fraction of precipitation that accumulates on the land surface by increasing the proportion of winter precipitation that falls as rain and increasing snowmelt during the cold season. The resulting reduced spring snowpack leads to declining summer streamflow and increasing flood risks during winter and early spring (Barnett et al. 2005; Kang et al. 2016; Najafi and Moradkhani 2015). This, in turn, leads to water 
shortages in the dry season that may cause problems in water resource allocation and ecosystem maintenance, and shifts in flow peaks may threaten the safety of infrastructure and undermine current floodplain management strategies.

Analyses of observed global datasets show an overall declining trend in Northern Hemispheric spring snow cover extent (SCE) that is intensified at higher latitudes because of larger albedo feedbacks (Hernández-Henríquez et al. 2015; Vaughan et al. 2013). Previous studies have shown decreasing trends in the SCE (Groisman et al. 1994; Groisman et al. 2004) and snow water equivalent (SWE) in the western United States and Canadian Rockies (Déry et al. 2009; Mote et al. 2005; Pierce et al. 2008). Pederson et al. (2011), studying paleo snowpack reconstructions for the past millennium, suggest that the recent rate of snowpack decline in the northern Rocky Mountains is unusual relative to rates of decline seen in the reconstructions over periods of similar length. Kang et al. (2014), who considered the ratio of the spatially averaged maximum SWE to runoff to indicate the contribution of snow to the runoff in the Fraser River basin, the largest basin in western Canada, also found significant declines during 1949-2006.

Studies of projected changes in hydroclimatic quantities that rely on coupled atmosphere-ocean general circulation model simulations report an earlier onset of spring snowmelt, a tendency toward more rainfall, particularly at medium and low elevations, and a general reduction in the spring SWE (Arora and Boer 2001; Merritt et al. 2006; Shrestha et al. 2012). There is also a tendency toward increased SWE at high elevations where temperature remains below the freezing level and precipitation is projected to increase, including in the current study domain (Schnorbus et al. 2014). All these studies inherently assume that models generate the "true" hydroclimatic responses to changes in climate.

Observed changes in the climate reflect the combined effects of different external forcing factors including anthropogenic factors such as greenhouse gas increases and natural factors such as solar variability and volcanic activity, as well as natural internal variability. Detection and attribution (D\&A) of climate change provides a means to identify hydroclimatic changes that are outside the range of the observed internal (i.e., unforced) variability and possibly attribute those changes to a specific combination of forcing factors. Furthermore, it assesses whether the amplitudes of climate-model-simulated responses to external forcing are consistent in magnitude with the observed changes (Bindoff et al. 2013; Zwiers et al. 2014).

Although human influence has been detected at global and continental scales in components of the hydrologic cycle and related variables such as temperature (Hegerl et al. 2007; Jones et al. 2013; Knutson et al. 2013; Najafi et al. 2015), snow cover extent (Najafi et al. 2016; Rupp et al. 2013), precipitation (Balan Sarojini et al. 2012; Fyfe et al. 2012; Marvel and Bonfils 2013; Min et al. 2008; Zhang et al. 2007), evaporation (Douville et al. 2013), and atmospheric moisture content (Santer et al. 2007), only a few hydrological detection and attribution studies have been performed on regional domains, partly because of the low signal-to-noise ratios at these scales (Stott et al. 2010). Previous studies have shown evidence for human influence in hydrological changes of the western United States [e.g., see the review of Das et al. (2009)]. Pierce et al. (2008) and Barnett et al. (2008) used two GCMs downscaled to daily temporal resolution and $1 / 8^{\circ}$ spatial resolution to simulate forced hydroclimatic changes in the western United States with the Variable Infiltration Capacity hydrologic model (VIC; Liang et al. 1996; Liang et al. 1994), and attributed observed changes in annual 1 April SWE values (SWE April_1st $_{1}$ ) normalized by the antecedent October-March total precipitation $\left(P_{\text {Oct-Mar }}\right)$ to anthropogenic forcing. Also, Hidalgo et al. (2009) found that anthropogenic influence had advanced the center timing of streamflow in this region.

The previous studies were conducted over a predominantly water-limited region part of western North America, where the atmospheric demand is greater than precipitation (Kumar et al. 2015). In addition, they were based on only two models that participated in phase 3 of the Coupled Model Intercomparison Project (CMIP3; Meehl et al. 2007). In this study, we investigate the contribution of climate change to the observed changes in snowpack in an energylimited (as opposed to water limited) part of western North America where precipitation is greater than the atmospheric demand for moisture. Also, we utilize a large set of CMIP5 (Taylor et al. 2012) simulations to better represent the uncertainties due to model errors and internal climate variability. We compare observed changes in normalized $\mathrm{SWE}_{\text {April_1st }}$ to changes that are expected as a consequence of forcing, where the expected changes are estimated from large ensembles of runs of a distributed hydrologic model, each of which was driven by a different GCM run. Each simulation reflects the combined effect of the response to the external forcing that was specified to the climate model and internal climate variability as simulated by that model. Since different climate models have different biases, and since realizations of internal variability in different climate model simulations should be independent, a multimodel average of a large ensemble of runs should provide a more robust estimate of the effects of forcing.

We use 10 GCMs that participated in CMIP5 and collectively provided 40 simulations with both anthropogenic and natural forcing combined (ALL), a further 40 simulations with natural forcing alone (NAT), and approximately $4200 \mathrm{yr}$ of preindustrial control 
simulations (CTL). All of these simulations were downscaled to daily $1 / 16^{\circ}$ horizontal resolution over British Columbia using the bias correction and spatial disaggregation (BCSD) approach (Maurer and Hidalgo 2008; Wood et al. 2002). The VIC hydrologic model, which was configured with $1 / 16^{\circ}$ horizontal resolution and a maximum of five elevation bands following Schnorbus et al. (2011), was then driven by the downscaled climate simulations over the Fraser, Peace, Upper Columbia, and Campbell River basins in BC, with a total drainage area of approximately $420000 \mathrm{~km}^{2}$. This resulted in 173 hydrologic model simulations (i.e., 40 ALL + 40 NAT + 93 45-yr CTL segments) for each basin. The simulated annual SWE $\mathrm{Spril}_{\text {1st }}$ values in each $1 / 16^{\circ}$ grid cell were divided by $P_{\text {Oct-Mar }}$ to obtain the fraction of precipitation that had accumulated as snow (i.e., normalized SWE or nSWE).

The magnitude and significance of trends in observed and simulated regional temperature and nSWE are assessed using the Sen's slope estimator and MannKendall nonparametric test (Helsel and Hirsch 1992; Najafi and Moazami 2016; Sen 1968) as modified by Zhang et al. (2000) to account for the effects of serial correlation. We apply the optimal fingerprinting (OF) approach (Allen and Stott 2003; Hasselmann 1997; Ribes and Terray 2013) for the D\&A analysis of nSWE and October-March mean temperature. In OF, the patterns of the observed hydroclimatic changes are projected onto model-simulated patterns of response to different forcing agents using a multilinear regression model. Several thousand years of preindustrial model simulations are generally required to estimate the covariance matrix of internal variability well (Bindoff et al. 2013), which is required to fit the regression model. The robustness of the results is evaluated by considering different observed datasets and by evaluating the sensitivity of results to the removal of the effects of teleconnected low-frequency variability prior to conducting the D\&A analysis.

Sections 2 and 3 describe the study area and the observed and simulated datasets. The methodologies for processing the datasets, downscaling, and optimal fingerprinting are described in section 4 . Section 5 discusses the results, and their robustness to the choice of observed datasets is assessed in section 6. Finally, section 7 presents some concluding remarks.

\section{Study area}

The four BC river basins considered in this study have distinct topographic and physiographic conditions (Fig. 1, Table 1). The snow-dominated Fraser River basin is the largest basin in the region, with a total drainage area of $230000 \mathrm{~km}^{2}$ and elevation that ranges from sea level to
$4000 \mathrm{~m}$. Average temperature ranges from $-8.9^{\circ} \mathrm{C}$ in January to $13.1^{\circ} \mathrm{C}$ in July (see Fig. 2) and mean annual precipitation varies between 200 and $5000 \mathrm{~mm}$ (Schnorbus et al. 2010). Approximately $51 \%$ of the annual precipitation in this basin falls as snow. The Peace River basin, with a drainage area of $101000 \mathrm{~km}^{2}$ and elevation ranging from 400 to over $2800 \mathrm{~m}$, has a continental climate with average temperature ranging from $-11.7^{\circ} \mathrm{C}$ in January to $12.4^{\circ} \mathrm{C}$ in July. Approximately $51 \%$ of the annual precipitation in this basin falls as snow primarily during October-April. The Upper Columbia River basin $\left(86400 \mathrm{~km}^{2}\right.$; elevation range from 420 to over $3000 \mathrm{~m}$ ), has a humid-continental climate with average temperature ranging from $-9.2^{\circ} \mathrm{C}$ in January to $13.3^{\circ} \mathrm{C}$ in July. Approximately $61 \%$ of the annual precipitation falls as snow. Roughly $4 \%$ of the Upper Columbia River basin is covered by glaciers, and glacial runoff can contribute as much as $10 \%$ of annual discharge and up to $15 \%-20 \%$ of late summer (August-September) discharge. The Campbell River basin $\left(1193 \mathrm{~km}^{2}\right.$; elevation from 139 to over $2200 \mathrm{~m}$ ) has a temperate coastal climate with average temperature ranging between $-1.6^{\circ} \mathrm{C}$ in December to $15.1^{\circ} \mathrm{C}$ in August. Approximately $45 \%$ of the annual precipitation of $2960 \mathrm{~mm}$ falls as snow; $78 \%$ of precipitation falls during the period from October to March.

D\&A is performed separately over each individual basin and over the four basins combined.

\section{Data}

Daily gridded observed precipitation $(P)$ and minimum and maximum temperature ( $T_{\min }$ and $\left.T_{\max }\right)$ are generated at $1 / 16^{\circ}$ spatial resolution using the techniques described by Maurer et al. (2002) following Schnorbus et al. (2011). The gridded data are based on 1950-2006 station observations from Environment and Climate Change Canada (ECCC), the U.S. Cooperative Observer Network, and other regional agencies (Schnorbus et al. 2011). VIC also requires anemometer height $(10 \mathrm{~m})$ wind speed data. Since only limited in situ observations are available in comparison to precipitation and temperature, hydrologic modeling studies often resort to using spatially interpolated $10-\mathrm{m}$ wind speed data from a reanalysis product (Hamlet and Lettenmaier 2005; Maurer et al. 2002; Wood et al. 2002). We follow suit in this study, and obtain the 10-m wind speed data required by VIC from the National Centers for Environmental Prediction (NCEP)-National Center for Atmospheric Research (NCAR) reanalysis (Kalnay et al. 1996), which is regridded to $1 / 16^{\circ}$ resolution consistent with that of $P, T_{\min }$, and $T_{\max }$.

Manual snow survey SWE measurements are obtained at the beginning of each nonsummer month (8 times per year) by driving a tube through the snow and weighing the resulting snow core. $\mathrm{SWE}_{\text {April_1st }}$ 


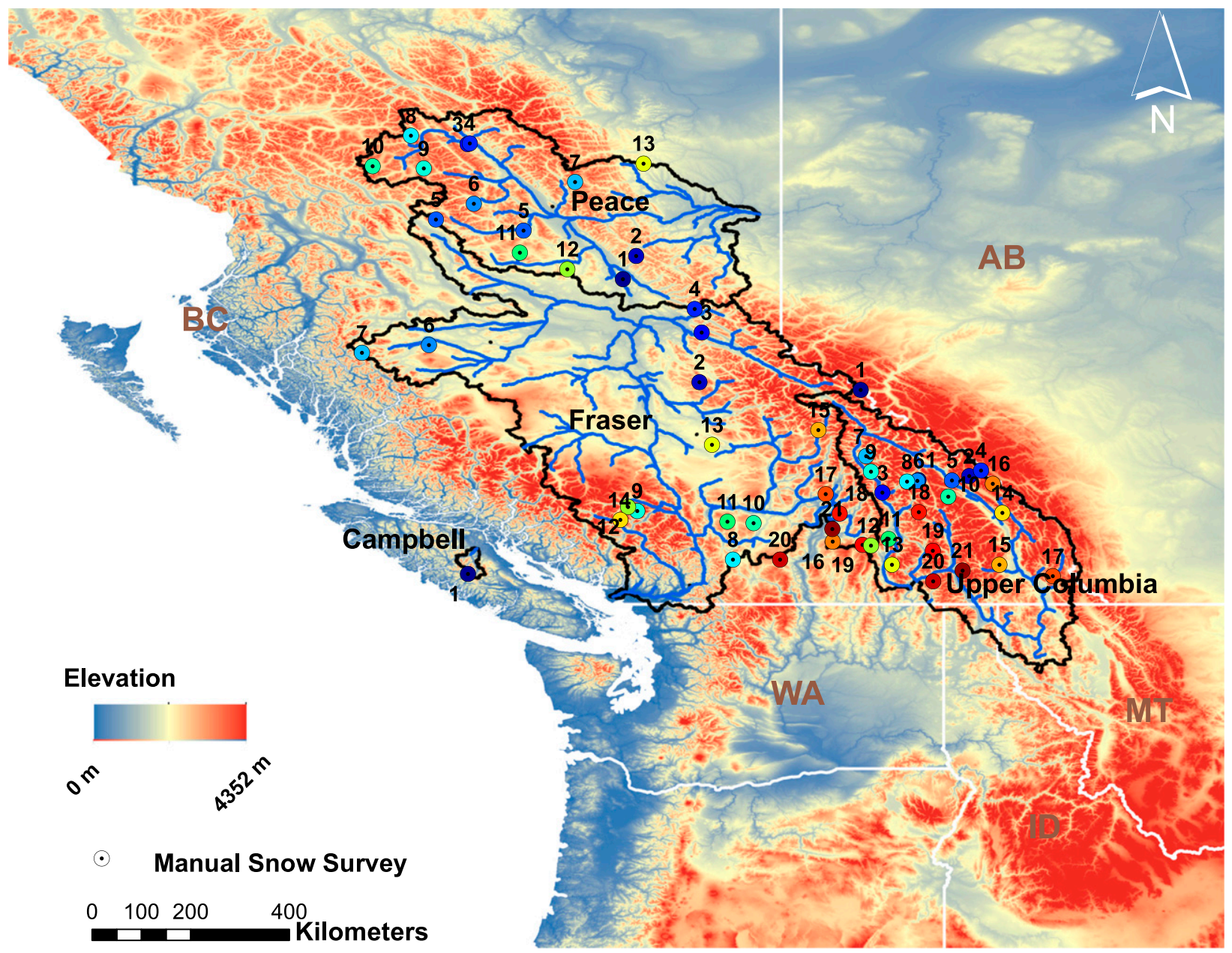

FIG. 1. Study area including Fraser, Peace, Upper Columbia, and Campbell River basins. The manual snow survey stations for each basin are numbered and color-coded, matching the color coding used in Figs. 4 and 5 so that stations can be identified in those figures.

is divided by the measured $P_{\mathrm{Oct}-\mathrm{Mar}}$ at the same location. The snow survey data we use are a product of the British Columbia Snow Survey Network Program distributed by the British Columbia River Forecast Center (http:// bcrfc.env.gov.bc.ca/data/), which is a unit of the British Columbia Ministry of Forests, Lands and Natural
Resource Operations. We analyze $45 \mathrm{yr}$ of SWE from 1961 to 2005 using 51 snow survey records (Fig. 1) that contain less than $18 \%$ missing data; the majority of locations have less than $12 \%$ data missing.

The formal detection and attribution approach uses 40 climate simulations that are driven with anthropogenic

TABLE 1. Characteristics of the four river basins during 1961-2005.

\begin{tabular}{|c|c|c|c|c|}
\hline Basin & Fraser & Peace & Columbia & Campbell \\
\hline Drainage area $\left(\mathrm{km}^{2}\right)$ & 230000 & 101000 & 86400 & 1193 \\
\hline Elevation range $(\mathrm{m})$ & $0-4000$ & $400-2800$ & $420-3000$ & $139-2200$ \\
\hline Coldest month & January & January & January & December \\
\hline Warmest month & July & July & July & August \\
\hline Percentage of annual precipitation falling as snow & 51 & 51 & 61 & 45 \\
\hline Annual precipitation $(\mathrm{mm})$ & 900 & 761 & 1150 & 2700 \\
\hline Percentage of precipitation received between October and March & 53 & 46 & 58 & 78 \\
\hline Average minimum temperature $\left({ }^{\circ} \mathrm{C}\right)$ & -32.5 & -36.6 & -29.7 & -13.8 \\
\hline Average maximum temperature $\left({ }^{\circ} \mathrm{C}\right)$ & 29.5 & 27.7 & 29.5 & 28.2 \\
\hline
\end{tabular}


and natural external forcing, 40 simulations with natural external forcing alone, and approximately $4200 \mathrm{yr}$ of control simulations (Table 2). We use the 1961-2005 period from each forced simulation and correspondingly divide the control simulations into $9345-\mathrm{yr}$ "chunks." The $P, T_{\min }$, and $T_{\max }$ values from each simulation are downscaled to drive VIC (discussed in the following sections) to generate the changes in $\mathrm{nSWE}$ in each basin. The 40-member ensemble of ALL nSWE simulations is then averaged to obtain an estimate of the response in nSWE to ALL forcing. An estimate of the response to NAT forcing is obtained similarly. Internal unforced nSWE variability is estimated from the 93 simulations that are obtained using CTL-run-derived driving data.

\section{Methodology}

\section{a. Downscaling ALL, NAT, and CTL}

Forty-five-year time series of monthly mean $P, T_{\min }$ and $T_{\max }$, from the ALL, NAT, and CTL simulations are downscaled to daily temporal and $1 / 16^{\circ}$ spatial resolution using BCSD. Monthly $P$ and $T$ are first bias corrected using a nonparametric quantile mapping method by aggregating the $1 / 16^{\circ}$ observations to the scale of the GCMs and developing the CDFs of the observed and simulated datasets separately for each month. The resulting biascorrected GCM monthly means are then spatial disaggregated. This is achieved by first calculating the differences (for $T$ ) or ratios (for $P$ ) between the monthly GCM simulations and the climatology of the aggregated observations for the corresponding month, and then applying the observed $1 / 16^{\circ}$ grid cell climatology to those monthly anomalies. Temporal disaggregation was conducted by randomly selecting month-long sequences from the daily observational record and scaling (for $P$ ) or shifting (for $T$ ) them to match the bias-corrected and spatially disaggregated monthly time series. The same observed month is used for precipitation and temperature to ensure physical consistency between the downscaled precipitation and temperature values produced with BCSD. Error checking was performed on the precipitation scaling factors and by screening the number of wet days following (Maurer and Hidalgo 2008; Wood et al. 2002).

\section{b. Hydrologic modeling}

Hydrologic modeling is performed using VIC (version 4.0.7) for each basin from 1961 to 2005 . VIC (Liang et al. 1994, 1996) is a semidistributed land surface model that is driven by the downscaled $P, T_{\min }$, and $T_{\max }$ from ALL, NAT, and CTL as well as the
TABLE 2. CMIP5 climate models that provide climate simulations with historical variations in all forcing agents combined and historical natural forcing (ALL-NAT) changes as well as preindustrial simulations (CTL); the same number of runs were used based on ALL and NAT. (Expansions of acronyms are available online at http://www.ametsoc.org/PubsAcronymList.)

\begin{tabular}{lcc}
\hline \hline Climate model & $\begin{array}{c}\text { ALL-NAT } \\
\text { ensemble } \\
\text { size }\end{array}$ & $\begin{array}{c}\text { CTL ensemble } \\
\text { size of 45-yr } \\
\text { chunks }\end{array}$ \\
\hline BCC_CSM1.1 & 1 & 7 \\
CanESM2 & 5 & 14 \\
CCSM4 & 4 & 16 \\
CNRM-CM5 & 6 & 11 \\
CSIRO Mk3.6.0 & 5 & 7 \\
GFDL CM3 & 3 & 7 \\
GISS-E2-R-CC & 10 & 17 \\
HadGEM2-ES & 4 & - \\
MRI-CGCM3 & 1 & 7 \\
NorESM1-M & 1 & 7 \\
\hline
\end{tabular}

regridded estimates of $10-\mathrm{m}$ wind speed from the NCEP-NCAR reanalysis (Kalnay et al. 1996). For each month, the daily wind speeds that are used are those that correspond to the randomly selected month that provided the daily precipitation and temperature variations for that month, again to ensure physical consistency between all aspects of the VIC driving data. VIC also requires information about the physical characteristics of the watershed, such as the land cover, soil depth, elevation, etc. Further information about the current model setup is provided by Schnorbus et al. (2011) and Shrestha et al. (2012). SWE output from VIC driven by observed gridded $P$ and $T$ is considered as pseudo-observations and is referred to as reconstructed SWE in the remainder of this paper.

VIC was initially developed as a land surface scheme to be incorporated in GCMs. The current model considers subgrid variability in land cover, soil-moisture storage, precipitation, and elevation. Each grid cell is partitioned into five elevation bands containing a number of land cover tiles. Each land cover type consists of a vegetation layer and several soil layers (commonly three soil layers are used; Cherkauer et al. 2003; Najafi and Moradkhani 2014). The land cover tiles are described based on leaf area index (LAI), albedo, canopy resistance, roughness length, etc. Spatial variability of infiltration and runoff generation is simulated using a variable infiltration curve within each vegetation class. The Penman-Monteith equation (Monteith 1965), with no canopy resistance, is used to calculate potential evapotranspiration, which is dependent on the net radiation, vapor pressure deficit, and aerodynamic resistance. The sum of evaporation from the canopy layer, transpiration from the vegetation classes, and evaporation from the bare soil, weighted by the 
corresponding surface cover area fractions, constitutes the total simulated evapotranspiration.

VIC uses a daily time step. It includes a snow algorithm with a two-layer formulation consisting of surface and pack layers and represents the surface energy balance at the snow-air interface along with the heat flux from the snowpack into the ground assuming that the surface temperature and the overlying surface air temperature are equal.

\section{c. Optimal fingerprinting for detection and attribution}

To increase the signal-to-noise ratio, gridded observed $P_{\text {Oct-Mar }}$ and observed or reconstructed SWE $\mathrm{SWril}_{\text {Ast }}$ on the $1 / 16^{\circ}$ grid are averaged across the individual basins and used to calculate annual nSWE values for each basin. Annual nSWE and 5-yr nonoverlapping nSWE averages are used for D\&A. All VIC simulations were similarly processed.

The detection of changes in nSWE and attribution of those changes to external forcing is based on optimal fingerprinting using the total least squares approach (Allen and Stott 2003; Najafi et al. 2015; Ribes et al. 2013). Here, observed nSWE is projected onto the estimated patterns of response to external climate forcing using the generalized linear regression model:

$$
\mathbf{n S W E} \mathbf{\mathrm { obs }}_{1}=\beta_{1} \mathbf{n S W E}_{\mathrm{ALL}}+\beta_{2} \mathbf{n S W E}_{\mathrm{NAT}}+\boldsymbol{\varepsilon},
$$

in which $\mathbf{n S W E} \mathbf{E}_{\text {obs }}$ denotes the vector of the observed nSWE anomalies, $\mathbf{n S W E}_{\mathrm{ALL}}$ and $\mathbf{n S W E}_{\mathrm{NAT}}$ are vectors representing the multimodel ensemble mean of the responses to ALL and NAT, respectively, and the vector of residuals $\varepsilon$ represents the variation in $\mathbf{n S W E} \mathbf{E}_{\text {obs }}$ due to internal (i.e., unforced) variability.

Interpretation of the fitted regression model is based on the estimated scaling factors $\beta_{i}$, and their corresponding uncertainty intervals, both of which rely on the correct estimation of the covariance matrix of internal climate variability. A scaling factor with a $5 \%-95 \%$ confidence interval that exceeds zero indicates that the corresponding response is detected in the observations. Scaling factors close to unity with small uncertainty ranges imply that the observed changes might be attributable to the corresponding forcing factor provided other potential causes can be eliminated (see, e.g., Mitchell et al. 2001). Scaling factors corresponding to ANT and NAT, and their corresponding confidence intervals, are estimated through decomposing $\mathbf{n S W E} \mathbf{E}_{\mathrm{ALL}}$ into $\mathbf{n S W E} \mathbf{E}_{\mathrm{ALL}}=$ $\mathbf{n S W E}_{\mathrm{ANT}}+\mathbf{n S W E}_{\mathrm{NAT}}$, which results in $\beta_{\mathrm{ANT}}=\beta_{1}$ and $\beta_{\mathrm{NAT}}=\beta_{1}+\beta_{2}$.
The total least squares approach takes into account the effect of model internal variability (denoted $\varepsilon_{\mathrm{nSWE}}$ and $\varepsilon_{\mathrm{nSWE}} \mathrm{NAT}_{\mathrm{N}}$ below) in the multimodel ensemble mean of a finite number of climate simulations with a given combination of climate forcing agents:

$$
\begin{aligned}
\mathbf{n S W E}_{\mathrm{ALL}} & =\mathbf{n S W E}_{\mathrm{ALL}}^{*}+\boldsymbol{\varepsilon}_{\mathrm{nSWE}_{\mathrm{ALL}},}, \\
\mathbf{n S W E}_{\mathrm{NAT}} & =\mathbf{n S W E}_{\mathrm{NAT}}^{*}+\boldsymbol{\varepsilon}_{\mathrm{nSWE}_{\mathrm{NAT}}},
\end{aligned}
$$

in which $\mathbf{n S W E}_{\mathrm{ALL}}^{*}$ and $\mathbf{n S W E}_{\mathrm{NAT}}^{*}$ are the true model responses based on an infinite ensemble of simulations.

Two full-rank covariance matrix estimates, $\widehat{\mathbf{C}}_{1}$ and $\widehat{\mathbf{C}}_{2}$, where $\mathbf{C}=\operatorname{Cov}(\boldsymbol{\varepsilon})$, are constructed using half of the available control simulations for each. One matrix is used to estimate $\beta_{1}$ and $\beta_{2}$, and consequently $\beta_{\mathrm{ANT}}$ and $\beta_{\mathrm{NAT}}$, and the second is used to determine their confidence intervals and perform a residual consistency test to compare model-simulated internal variability with that estimated from observations (Allen and Stott 2003; Ribes and Terray 2013).

We evaluate the robustness of our attribution results by applying the method to the following different observational datasets:

1) basin averages of manual snow survey records that are calculated as simple means of available point values normalized by precipitation averaged across grid cells at similar locations (MSS);

2) the VIC-reconstructed SWE averaged over grid cells that correspond to the manual snow survey sites (point measures) normalized by the corresponding average precipitation values (nSWEP); and

3) the VIC-reconstructed SWE averaged over the entire basin area normalized by the spatial average gridded precipitation (nSWEA).

\section{Results}

The monthly observed climatology of the spatially averaged temperature, precipitation, and the reconstructed SWE is shown in Figs. 2a-c. Direct comparison between the basin average reconstructed SWE (SWEA in Fig. 2c) and snow survey observations ( $\left.\mathrm{SWE}_{\mathrm{MSS}}\right)$ is difficult because the 1 April manual snow survey records are only available at specific points that are not necessarily representative of the entire basin. A more appropriate comparison is therefore made in Fig. 2d, where we show climatological $\mathrm{SWE}_{\mathrm{MSS}}$ and the corresponding reconstructed SWE (SWEP). As can be seen, the bias of the climatological SWEP is relatively small, with slight underestimation for the Fraser and Peace River basins. 
(a)

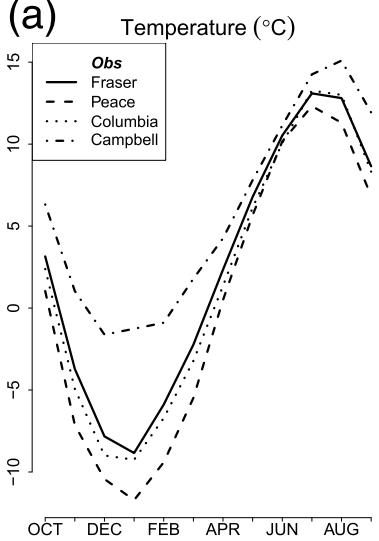

(b)

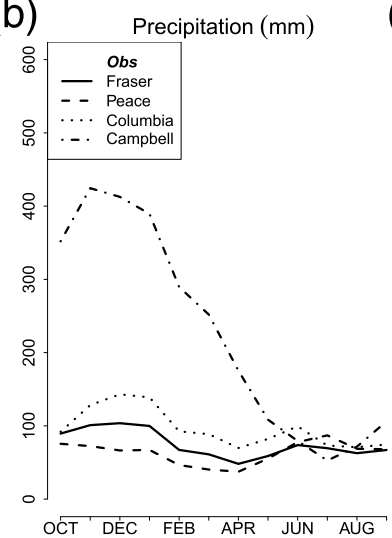

(c)

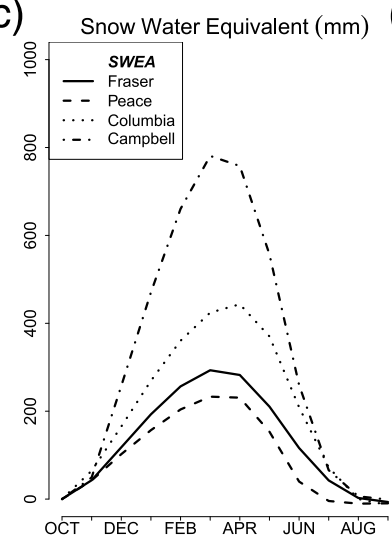

(d)

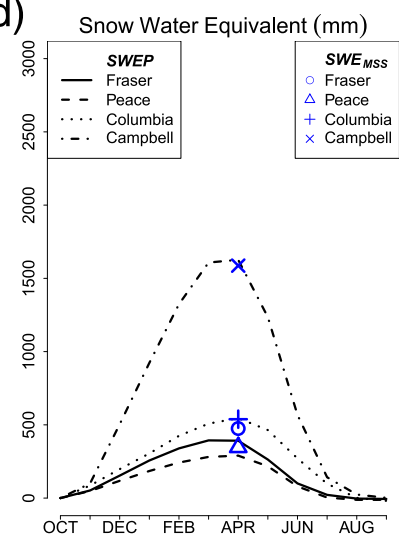

FIG. 2. Monthly observed climatology of the (a) spatially averaged mean temperature, (b) precipitation, (c) VIC-reconstructed SWE averaged across the whole domain (SWEA), and (d) manual snow survey and the corresponding VIC-reconstructed SWE averaged across each basin (SWE ${ }_{\text {MSS }}$ and SWEP) for 1961-2005: Fraser (solid), Peace (dashed), Columbia (dotted), and Campbell (dot-dashed) Rivers

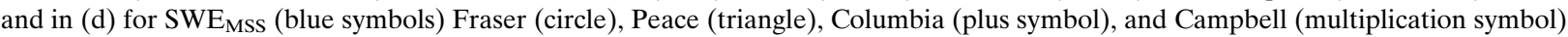
Rivers.

The spatial distributions of the climatologicalreconstructed $\mathrm{SWE}_{\text {April_1st }}$ (hereafter simply referred to as SWE), $P_{\text {Oct-Mar, }}$, and nSWE are shown in Fig. 3. The highest climatological precipitation values, exceeding $1000 \mathrm{~mm}$, as well as the corresponding SWE, occur in parts of Campbell and at high elevations in the southwestern, northwestern, and eastern Fraser, the northwestern Columbia, and the southeastern Peace River basins. Lower-elevation areas such as the central Fraser and southeastern Peace River basins show small amounts of accumulated snow as well as low precipitation. In areas where $\mathrm{nSWE} \geq 0.5$, the majority of winter precipitation remains in the form of snow until 1 April. High-elevation areas with perennial snow and glaciers show nSWE values that are larger than unity. It should be noted that there are substantial uncertainties in the gridded observed precipitation and temperature datasets, particularly at high elevations. These uncertainties arise because observing stations are sparse in many regions, and tend to be located at lower elevations that might not properly represent the climate variability in grid cells with higher elevations (Schnorbus et al. 2011).

\section{a. Performance of VIC for snow simulation}

The manual snow survey record at each site is compared with the reconstructed SWE at the grid cell that includes that site in order to evaluate the VIC-simulated SWE (Figs. 4 and 5). The majority of the snow survey measurements are taken at higher elevations (see Fig. 1) and the reconstructed SWE at these locations is influenced by uncertainties in the driving gridded observations as well as the hydrological model structure and parameterization. Also, climate variability is large at high elevations, adding an additional source of uncertainty (Diaz 2003). As shown in Fig. 4, the observed SWE climatology is underestimated

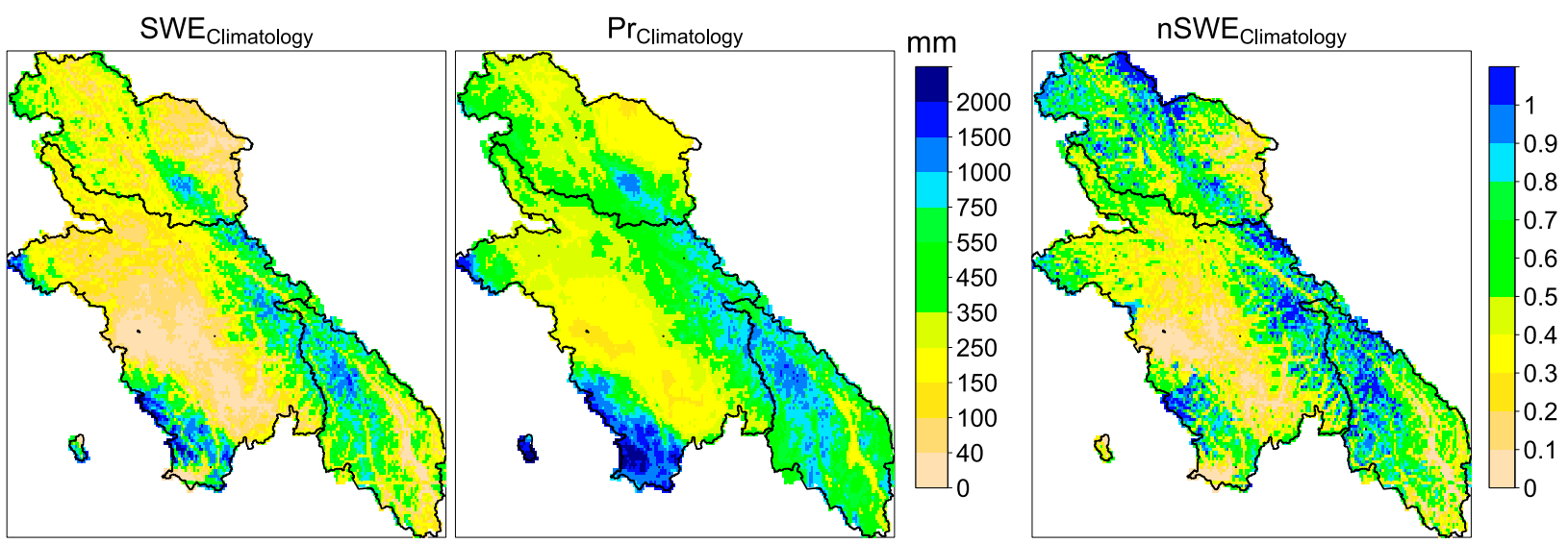

FIG. 3. Spatial distribution of the (left) mean VIC-reconstructed SWE $\mathrm{April} \_1 s t_{\text {, }}$ (center) gridded observed October-March total precipitation $\mathrm{Pr}_{\text {climatology, }}$ and (right) the normalized SWE (nSWE) over the four basins for 1961-2005. 

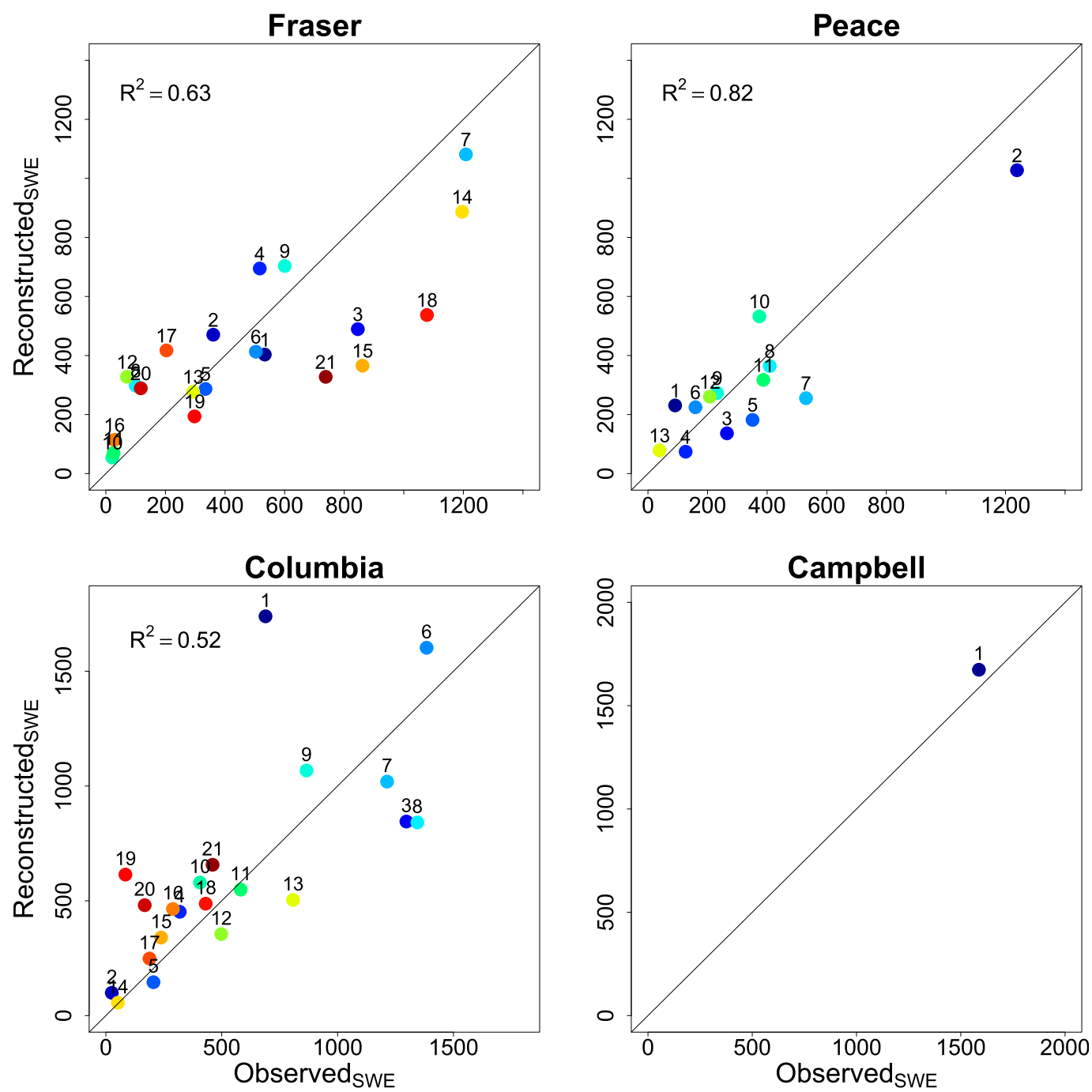

FIG. 4. Observed SWE climatology for 1961-2005 based on manual snow survey records compared with reconstructed SWE at the corresponding $1 / 16^{\circ}$ grid cells; the points are colored and numbered according to the snow survey sites in Fig. 1.

at several high-elevation sites in the southeastern and northwestern Fraser River basin (e.g., sites 21, 15, 3, 18, and 7), while the climatology at neighboring sites in the southwestern Fraser River basin is underestimated in one case (site 14) and overestimated at others (sites 12 and 9). There is, however, reasonable consistency overall between the climatology of the observed and reconstructed SWE with coefficients of determination $\left(R^{2}\right)$ of $0.63,0.81$, and 0.47 corresponding to the Fraser, Peace, and Columbia River basins. A large portion of the Columbia River basin lies at high elevation, which as noted previously could result in higher uncertainties in the climatology of the reconstructed SWE due to the uncertainties in the gridded observations and high elevation climate variability. There is only about $5 \%$ bias in the reconstructed SWE climatology in the Campbell River basin.
Observed annual SWE anomalies from the 1961-2005 climatology are compared with the corresponding reconstructed annual SWE anomalies to show the performance of VIC in characterizing the variability in SWE (Fig. 5). There is good consistency in annual SWE anomalies in the Campbell with $R^{2}=0.65$ as well as in the Fraser and Columbia with $R^{2}=0.42$ and 0.53 , respectively. The consistency between observed and reconstructed SWE anomalies is weaker in the Peace with $R^{2}=0.25$.

\section{b. Temperature and nSWE trends}

Here we address the question of whether there have been detectable changes in regional SWE, a major component of natural seasonal water storage in western Canada. Anthropogenic forcing may drive changes in 

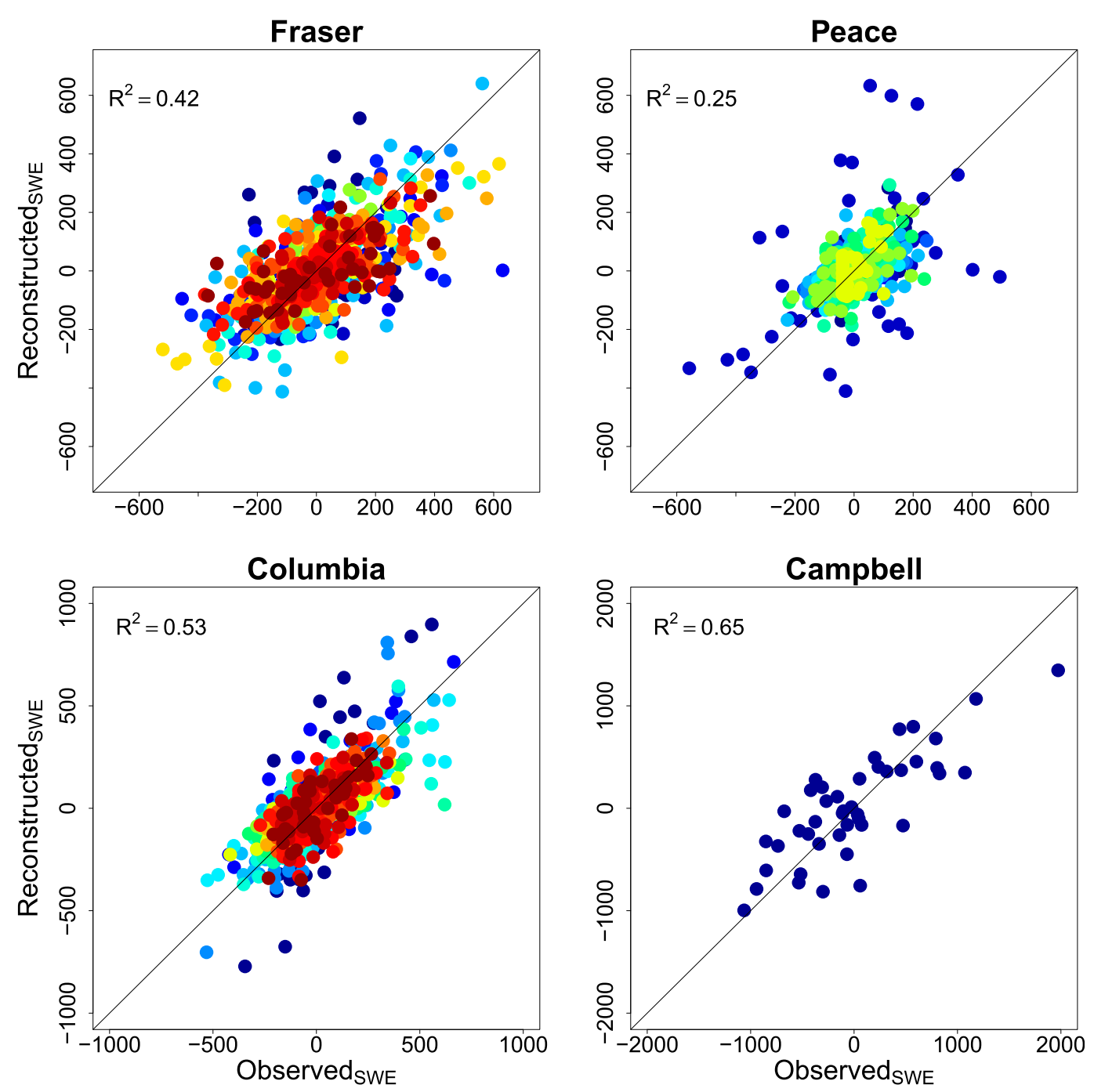

FIG. 5. As in Fig. 4, but based on observed annual SWE April_1st $_{\text {anomalies. }}$

precipitation, and an anthropogenic influence has been detected at high northern latitudes (Min et al. 2008). We focus on the proportion of precipitation that accumulates as snow, since this is expected to be more strongly influenced by temperature. Regional temperature changes can affect snow accumulation through several processes. As the climate warms, there is a higher probability that the winter precipitation falls as rain rather than snow, and that snowmelt occurs earlier in spring. The spatial distribution of the observed OctoberMarch daily mean temperature trend is displayed in Fig. 6, which shows an overall warming trend in $T_{\text {mean }}$ over the region during the 1961-2005 period. The increases range from $0.5^{\circ}$ to $1.5^{\circ} \mathrm{C}$ in large areas of the Columbia and Fraser River basins to more than $2^{\circ} \mathrm{C}$ in the Peace as well as northern parts of the Fraser River basins. The multimodel ensemble average of the downscaled ALL simulations also shows warming throughout the study area, although with lower rates ranging from $0.5^{\circ}$ to $1.5^{\circ} \mathrm{C}$. The climate simulations that are based only on NAT forcing show weak temperature trends.

Note that nSWE shows similar declining trends over most of the study region in reconstructed observations and in ALL-forcing simulations (Fig. 7). In contrast, nSWE shows a weak increasing trend in NAT simulations that is inconsistent with reconstructed observations. Spatial noise in reconstructed nSWE likely reflects uncertainty in the observational driving data from which nSWE is generated, the effects of topography (which can also be seen in the multimodel mean nSWE under ALL forcing), and internal variability. The latter source of noise is largely eliminated from the multimodel means as a consequence of averaging across 40 simulations. 

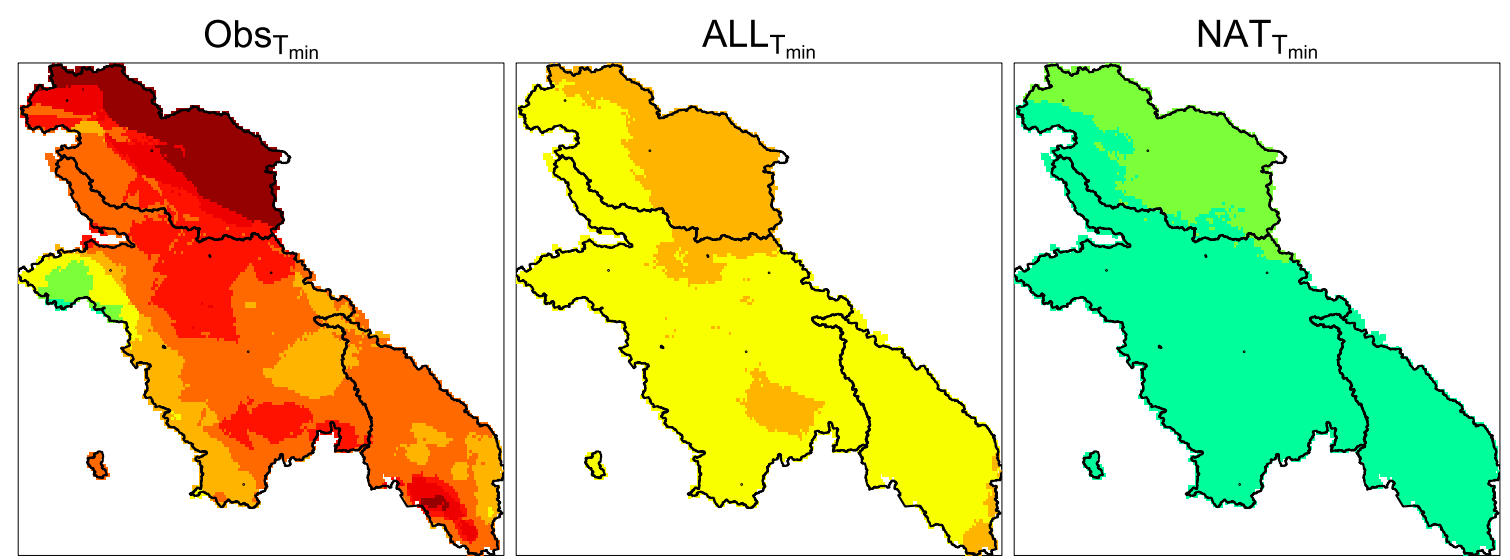

${ }^{\circ} \mathrm{C}$

FIG. 6. Spatial distribution of the trend in October-March mean daily average temperature over 1961-2005 using the nonparametric Sen's slope estimator based on (left) gridded observations, (center) downscaled simulations with anthropogenic and natural forcing combined, and (right) downscaled simulations with natural forcing alone. Note that ALL and NAT represent trends in multimodel average of 40 ensemble members whereas observations represent the trend in a single realization of the climate.

Figure 8 compares the trend in MSS, nSWEA, and nSWEP with the ranges of corresponding trends in ALL, NAT, and CTL simulations. The first and third interquartile ranges of CTL and NAT simulations include zero, indicating no particular trend when anthropogenic-forcing effects are not included. The ALL simulations, however, show decreasing nSWE, consistent with the observations. The observed trend in nSWEA (Fig. 8a) is close to the median of trends that are simulated under ALL forcing in the Peace while it is larger than the median simulated trend in the Fraser, Campbell, and Columbia to differing extents. Observed MSS and nSWEP (Fig. 8b) show larger declines compared to nSWEA and to their corresponding ALL simulations, except for the Peace where nSWEA shows a slightly larger decline compared to nSWEP.
The largest discrepancy is seen in the Columbia River basin (Fig. 8), where only one of 40 simulations exhibits a larger trend than seen in the reconstructed nSWE. The Columbia River basin exhibits less intersimulation variability in nSWE trends than in other basins (which is also evident when examining control runs). Mote (2003) showed that changes in SWE are more susceptible to temperature variations at lower elevations, where the mean temperature is close to the freezing levels, and consequently the magnitude of the SWE trend decreases with elevation. The magnitudes of the ALL-simulated nSWE trends (see Fig. S1 in the supplemental material) show similar relationships with elevation, except in the Campbell River basin, which has the smallest elevation range. The dependence of nSWE changes on elevation is weaker at altitudes above

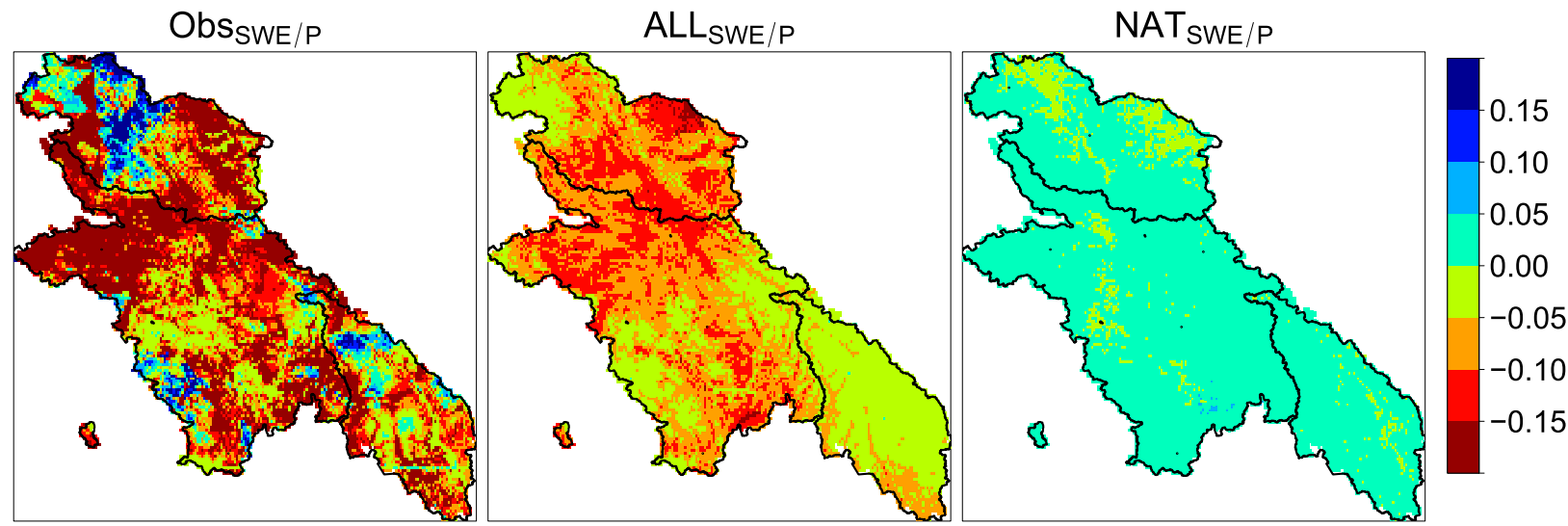

FIG. 7. Spatial distribution of the trend in the VIC-reconstructed SWE April_1st $_{\text {and }}$ normalized by the observed total October-March precipitation (Obs) for 1961-2005, as well as multimodel ensemble averages of ALL and NAT simulations. 
(a) Simulated nSWE vs. nSWEA
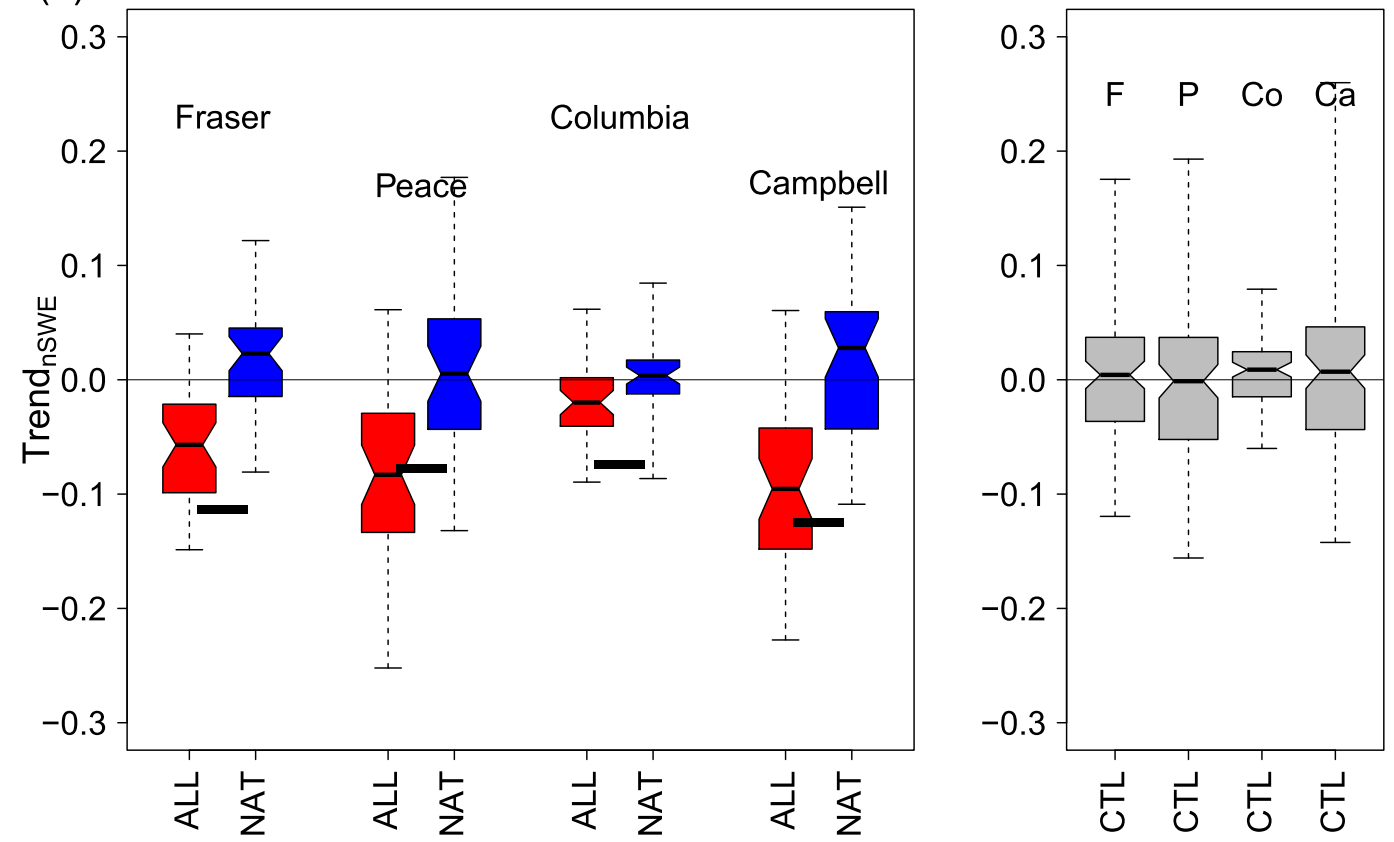

(b)

Simulated nSWE vs. MSS/nSWEP
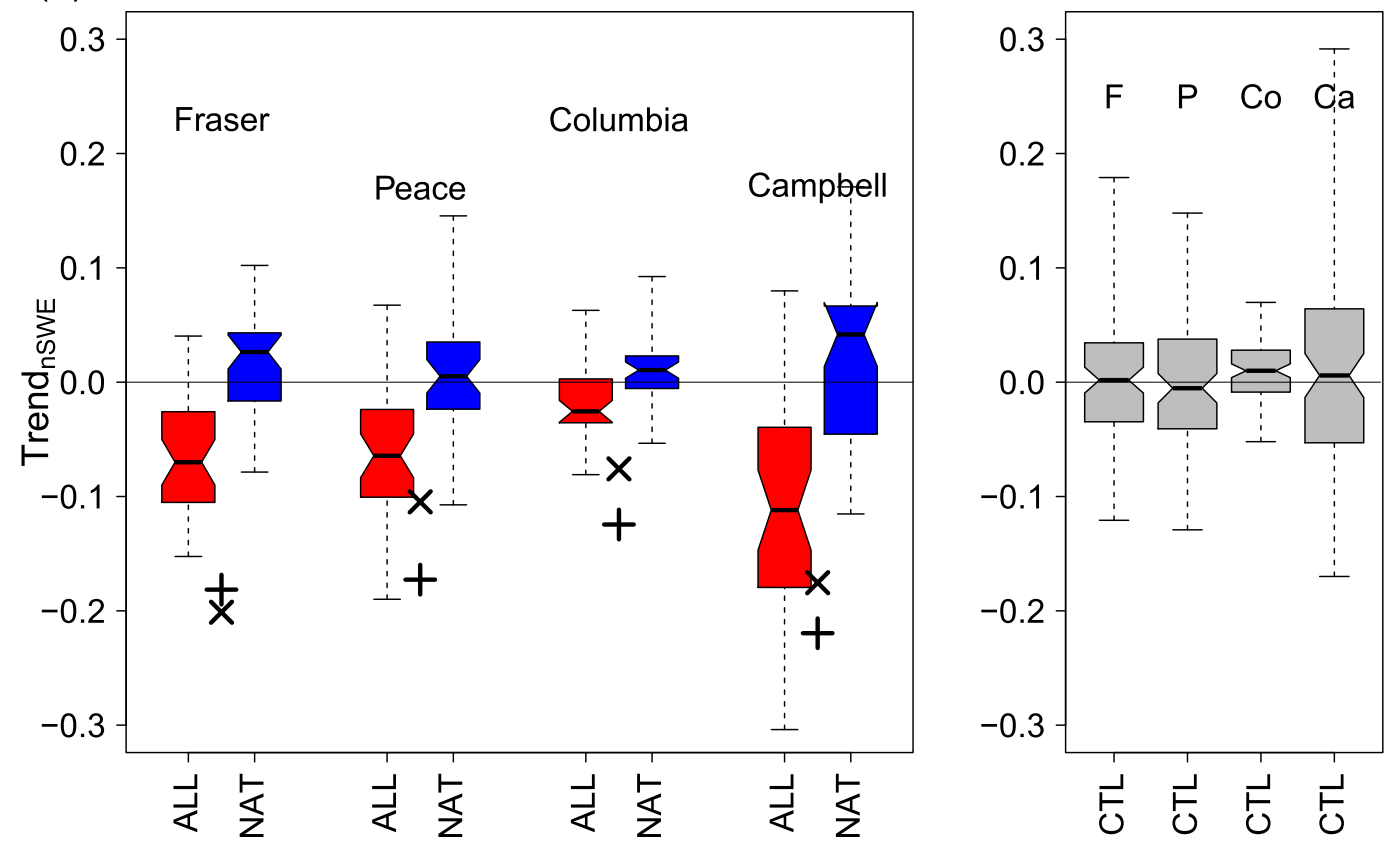

FIG. 8. Box-and-whisker plots of the trend in (a) basin mean nSWE based on each of the responses to (left) ALL and NAT forcing (40 ensemble members) as well as (right) preindustrial simulations (93 ensemble members) compared with that of the reconstructed nSWE (represented by horizontal black bars); and (b) as in (a), but based on observed and simulated nSWE averaged across MSS locations (multiplication and plus symbols represent MSS records and nSWEP, respectively); box-and-whisker plots show the maximum-minimum values (whiskers), the first and third quartiles, and the medians of the ensembles. Box-and-whisker plots with nonoverlapping notches indicate that they have statistically different medians (at the $5 \%$ significance level). 
TABLE 3. Observed and simulated nSWE trends for 1961-2005 averaged over different elevation zones.

\begin{tabular}{|c|c|c|c|c|c|c|}
\hline Elevation (m) & $<700$ & 700-1000 & $1000-1200$ & $1200-1500$ & 1500-1800 & $>1800$ \\
\hline Obs & -0.13 & -0.15 & -0.13 & -0.1 & -0.06 & -0.05 \\
\hline ALL & -0.08 & -0.09 & -0.09 & -0.07 & -0.04 & -0.01 \\
\hline NAT & 0.01 & 0.01 & 0.01 & 0.01 & 0.01 & 0.01 \\
\hline
\end{tabular}

$1500 \mathrm{~m}$, such as seen in the Columbia River basin, which has a mean elevation of about $1600 \mathrm{~m}$ compared to 1190 , 1220 , and $910 \mathrm{~m}$ for the Fraser, Peace, and Campbell Rivers, respectively (see Fig. 1). This appears to have resulted in the low intersimulation variability that is seen in the Columbia River basin. The correlation between the observed and simulated nSWE trends also declines with increasing elevation with values of 0.54 to 0.28 and 0.1 corresponding to areas lower than $1000 \mathrm{~m}$, between 1000 and $1500 \mathrm{~m}$, and more than $1500 \mathrm{~m}$, respectively. The larger declining trend in the observed nSWE compared to the ALL-simulated trends is consistent with differences between observed and ALL-simulated warming. Changes in observed nSWE in different elevation zones averaged across the study domain are shown in Table 3 together with corresponding ALL- and NAT-simulated changes. Regions below $1500 \mathrm{~m}$ show relatively large nSWE declines, with small variations in trends between elevation bands and with areas between 700 and $1000 \mathrm{~m}$ having the largest declines (based on both the observations and the ALL simulations). As noted above, regions above $1500 \mathrm{~m}$ show substantially weaker declines in nSWE with trend magnitudes that are less than half the trend magnitude in most elevation bands below $1500 \mathrm{~m}$. The nSWE trends based on the NAT simulations are minimal.

\section{c. Detection and attribution of $n S W E$ changes}

Basin averages of the annual nSWE anomalies are further averaged over nonoverlapping 5-yr intervals in order to increase the signal-to-noise ratio for the D\&A analysis. The resulting time series of $5-\mathrm{yr}$ mean nSWEA values are shown in Fig. 9. The observations show declining trends in all basins from 1975 onward. The ALL simulations show no substantial nSWE trends prior to the 1980 s, and have a declining trend from the 1980s to 2005 . The observed variability is generally within the range of variations of ALL simulations, but tends toward the lower $5 \%$ of NAT simulations, and occasionally falls below that level in the last $10-15 \mathrm{yr}$ of the record in the Fraser, Columbia, and Campbell River basins.

The nSWEA time series are regressed onto the simulated responses to ALL and NAT forcing to determine whether the effects of ANT, NAT, and ALL forcing are reflected in the observations. The first question is whether the response to ALL forcing is detectable in observations by means of a one-signal analysis. The resulting regression scaling factor estimates for the Fraser, Peace, Columbia, and Campbell River basins individually and for the whole region (labeled BC) are displayed in Fig. 10. The observed and simulated signals that are used for BC are calculated as the weighted average of the individual signals for each basin according to their drainage areas, with Fraser, Peace, Columbia, and Campbell River basins receiving weights of

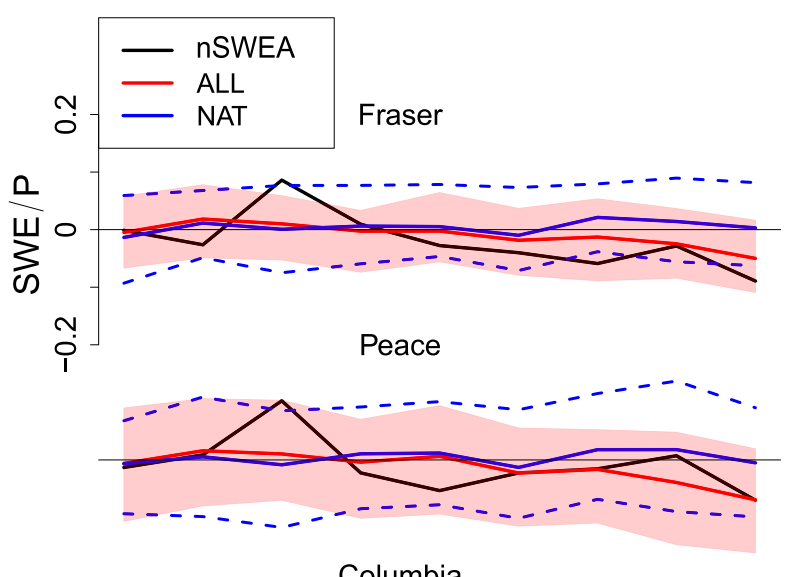

Columbia
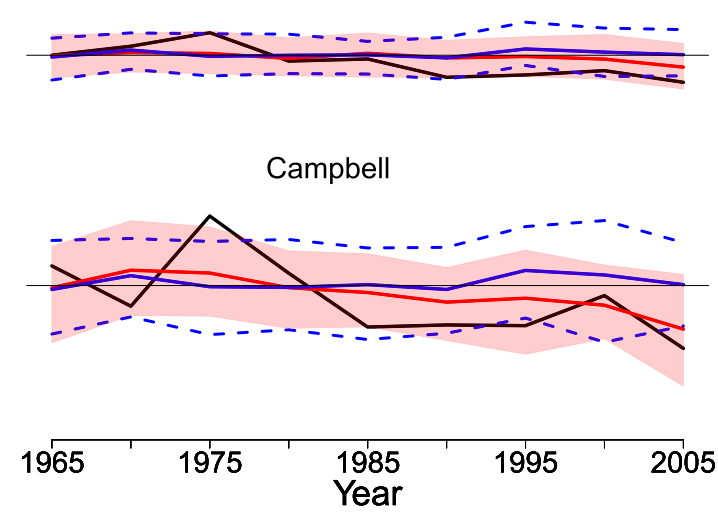

FIG. 9. Reconstructed 5-yr mean basin average nSWE anomalies (nSWEA) (black), compared with the mean simulated responses to ALL (red) and NAT (blue) forcing. Red shading and blue dashed lines represent the 5\%-95\% uncertainty ranges corresponding to ALL and NAT responses respectively. 


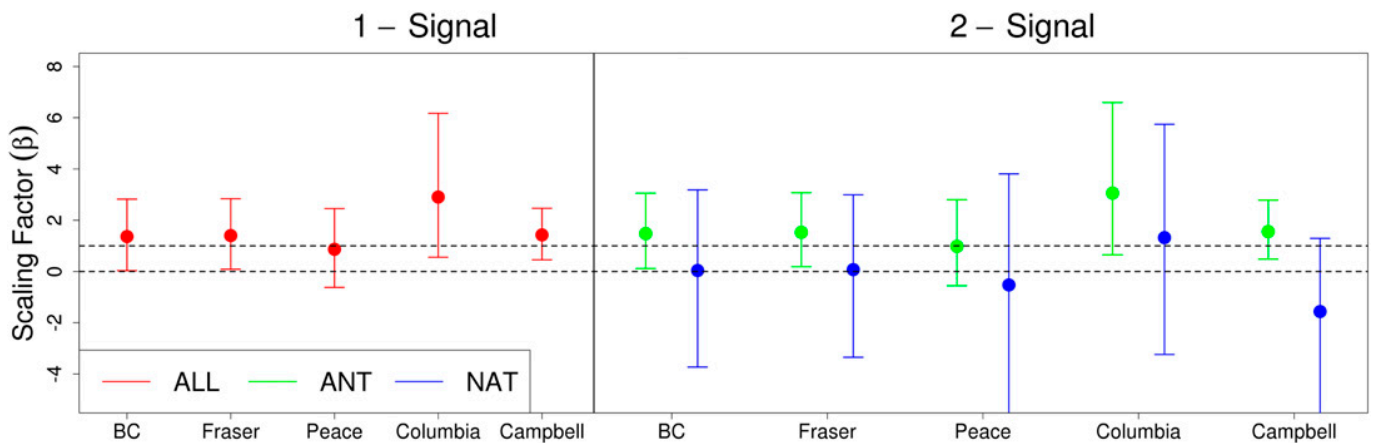

FIG. 10. Scaling factors-ranging from -4 to +8 in increments of 2 -and their corresponding $5 \%-95 \%$ confidence intervals computed by the optimal fingerprinting approach for (left) ALL (red) in a one-signal analysis, as well as (right) ANT (green) and NAT (blue) in a two-signal analysis. Time series of basin average 5-yr mean reconstructed normalized SWE for 1961-2005 is regressed onto multimodel mean simulated nSWE responses to ALL and NAT forcing using the total least squares approach. The multimodel mean responses for each forcing are based on a combined ensemble of 40 simulations from 10 models. Covariance matrices describing the variancecovariance structure of internal variability that are required to fit the regression models are estimated from an ensemble of $9345-\mathrm{yr}$ control simulations from the same 10 models.

approximately $55 \%, 24.1 \%, 20.6 \%$ and $0.3 \%$, respectively. In Fig. 10, best estimates are shown as circles and $90 \%$ confidence intervals are shown as bars. The response to ALL forcing is detected in BC as a whole and in the Fraser, Columbia, and Campbell River basins as indicated by uncertainty ranges that lie above zero. For the Fraser and Campbell River basins, the uncertainty bands are relatively narrow and are roughly centered on unity. The estimated scaling factor for the Peace River basin is also close to unity but has a somewhat wider uncertainty band that intersects zero, implying that it is not possible to formally detect the ALL-forcing signal in nSWE in that basin. The best estimate of the ALL scaling factor is consistent with unity in the Columbia River basin albeit with large uncertainty.

The second question is whether the individual influences of natural and anthropogenic forcing are discernable in the reconstructed nSWE. The two-signal analysis shows that the response to natural forcing alone is not detected as the $90 \%$ confidence intervals for the NAT scaling factors include zero in all cases. The responses to anthropogenic forcing, however, are detected in all observations except in the Peace River basin. These signals are consistent with unity in BC, Fraser, and Campbell, showing that the models have anthropogenic signal amplitudes that are consistent with those in reconstructed observations. The models underestimate the observed long-term nSWE change in the Columbia River basin, leading to ALL and ANT scaling factors that are substantially larger than unity. Overall these results suggest that the observed decline in the regional nSWE in western Canada from 1961 to 2005 can be attributed to the anthropogenic climate influence with reasonable confidence.

\section{d. Attribution robustness}

Attribution assessments are strongest when supported by multiple lines of evidence, when they are robust to the effects of possible confounding influences, and when consistent results are obtained across different observational datasets.

In this section we demonstrate that there is strong evidence that anthropogenic forcing was responsible for much of the October-March warming observed in the four basins, which supports the finding that anthropogenic forcing has acted to reduce nSWE over the 45-yr period that we analyzed. We next consider the robustness of our results to the choice of observational dataset. Finally, we evaluate the extent to which our results are robust to the removal of the influence of the Pacific decadal oscillation (PDO) on nSWE variations. This is important because the British Columbia climate is strongly influenced by the PDO (Vincent et al. 2015) and because of the possibility that variation in the PDO over the 1961-2005 analysis period could be confounded with anthropogenically forced secular change over this period.

\section{1) D\&A OF THE REGIONAL OCTOBER-MARCH TEMPERATURE}

Declining snowpack as a fraction of cold season total precipitation is an expected consequence of warming. The cold season temperature modulates the precipitation regime (snow vs rain) is expected to alter the total moisture transport into the basin (even when temperatures remain below zero) and affects snow and 


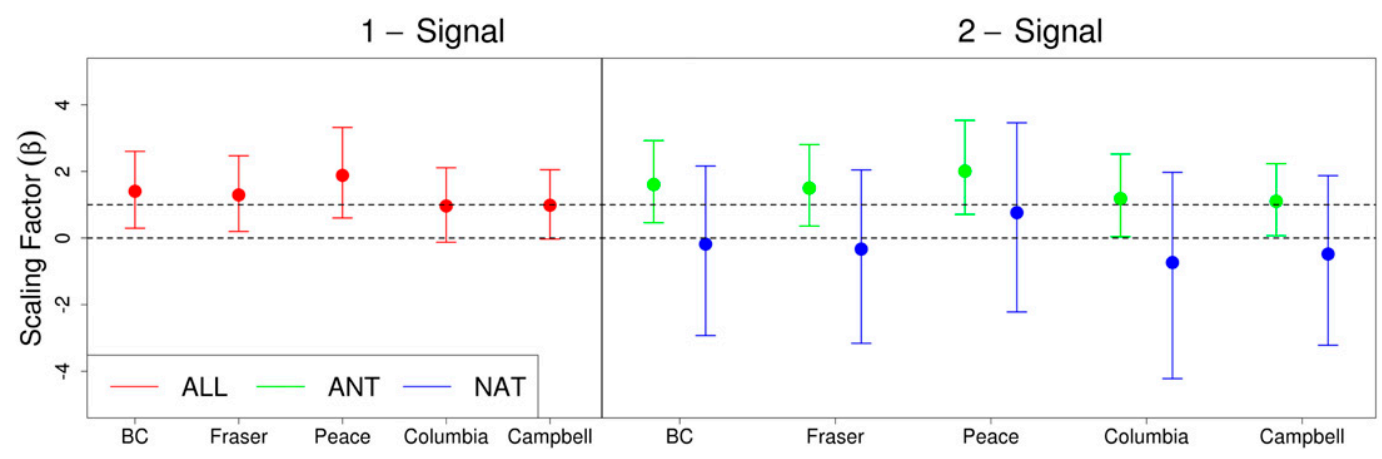

FIG. 11. As Fig. 10, but based on the October-March mean surface temperature.

ice melt, all of which affect the 1 April snowpack. Overall, daily mean temperature is above zero $30 \%$ of the time over the whole domain from October to the end of February $(25 \%, 18 \%, 18 \%$, and $55 \%$ corresponding to the Fraser, Peace, Columbia, and Campbell River basins). The temperature variation over OctoberMarch agrees better with global mean temperature variations ( $r=0.25,0.26,0.18,0.32$, respectively) compared to mean temperatures in shorter cold-season subperiods such as January-March $(r=0.14,0.14$, $0.11,0.25)$ or March alone $(r=-0.01,-0.03,0.07,0.08)$. Also, correlation analyses show that there is a strong relationship between the October-March temperature and nSWE anomalies (see Table S1 in the supplemental material). The October-March mean temperature averaged over the four basins combined has increased by $1.37^{\circ} \mathrm{C}$ with a $90 \%$ confidence interval of $\left[-0.23^{\circ} \mathrm{C}\right.$, $2.77^{\circ} \mathrm{C}$ ] over the 45 -yr study period. A D\&A analysis of cold season (October-March) temperature for this region over the same period demonstrates clearly that most of the observed cold-season warming for the region is attributable to anthropogenic forcing (Fig. 11). A onesignal analysis detects the response to ALL forcing in observed temperature changes of over BC, the Fraser and the Peace River basins. The responses to anthropogenic forcing can also be detected separately from the responses to natural forcing alone in a two-signal analysis in all basins. ALL and ANT scaling factors are consistent with unity in all cases, and the residual consistency test is passed in all cases.

\section{2) Choice of observational Data}

The anthropogenic influence in nSWE can be further verified using the manual snow survey records that are located at the sites shown in Fig. 1. Here, the simulated nSWE values based on ALL, NAT, and CTL simulations are considered based on grid cells that include the snow survey sites. Using snow survey records two major additional uncertainties arise: 1) The point measurements are compared with grid-based simulations that represent average SWE at the resolution of the grid cells over a domain with complex topography and 2) the snow survey records are sparse and might not represent the SWE variations over the region well. To evaluate the consistency between the point values with the small $1 / 16^{\circ}$ grid boxes that contain those points, we compare the averages of available snow survey data within basins with the corresponding averages of nSWEP. The time series of nonoverlapping 5-yr means of basin averages of nSWE based on MSS and nSWEP show larger declines compared to nSWEA (shown in Fig. 9), which generally fall to values below the lower $5 \%$ of NAT simulation during 1995-2005 (Fig. S2 in the supplemental material). There is reasonable consistency between MSS and nSWEP time series in all basins except in the Peace River basin where MSS shows slightly larger declines. Similar to nSWEA, the negative nSWE trend starts at about 1975 in the Columbia and Campbell River basins, but starts earlier in the Fraser and Peace River basins.

Optimal fingerprinting is again performed, this time on basin average MSS and nSWEP observations (Fig. S3 in the supplemental material). A pound sign (\#) above the scaling factor bars implies that the residual consistency test has failed and that the observational estimate of natural variability based on the residuals from the regression analysis is significantly lower than the variability obtained from the simulated runs. In the onesignal analyses, the response to ALL forcing is detected in $\mathrm{BC}$ and in the individual basins including the Peace River basin. However, models generally underestimate the ALL-forcing response as indicated by scaling factors greater than unity. In the two-signal analysis, the response to NAT forcing is not detected in the observations of the individual basins with scaling factors having large $90 \%$ confidence intervals that include zero. The response to ANT forcing, similar to nSWEA, is detected in all basins except for MSS-Peace and nSWEP-Columbia. The 
estimated scaling factors are greater than unity except in nSWEP-Peace and nSWEP-Campbell, suggesting that the models have underestimated the ANT response.

\section{3) REMOVing THE EFFECTS OF THE PDO}

We evaluate the effect of the PDO on the observed temperature and nSWE changes and assess the robustness of D\&A by removing its effects. To this end, observed nSWE and mean temperature are separately regressed against the October-March mean of monthly PDO index values, and D\&A analysis is performed on the estimated residuals. Since the phasing of PDO variability is expected to vary randomly between the individual climate simulations, its effects on the multimodel ensemble means should be negligible. Results show that the PDO explains about $2 \%, 0.7 \%, 2.3 \%$, and $0.9 \%$ of the October-March temperature variations over the Fraser, Peace, Columbia, and Campbell River basins respectively. Furthermore, about $6 \%$ (6\%), $0.3 \%$ (7.5\%), $2.5 \%(0.5 \%)$, and $0.8 \%$ $(1.5 \%)$ of the nSWE variations are explained by these signals according to snow survey (nSWEA) records for these basins. Anthropogenic influence is detected in the observed PDO-removed temperature and nSWE changes (Figs. S4-S6 in the supplemental material). While the response to ALL forcing is detected in PDO-removed temperature changes in each basin (Fig. S4), the 90\% confidence intervals for the ALL scaling factors obtained from the analysis of PDO-removed nSWEA are slightly too wide to allow ALL detection for BC and the Fraser River basin (Fig. S5). Nevertheless, the response to the anthropogenic forcing is discernable from the response to the natural forcing alone in both cases. Furthermore, we find that there is slightly better consistency between the ALL simulation and MSS after removing the PDO effect (Fig. S6).

\section{Conclusions}

In this study, a suite of $10 \mathrm{GCMs}$ that simulated the responses to both anthropogenic and natural forcing (ALL; 40 simulations) and to the natural forcing alone (NAT; 40 simulations) and provided approximately $4200 \mathrm{yr}$ of preindustrial control simulations (CTL) is downscaled to force the distributed Variable Infiltration Capacity hydrologic model over four river basins in British Columbia, western Canada. The magnitude and significance of the observed and simulated regional temperature and normalized SWE (nSWE) trends are assessed followed by a formal detection and attribution based on the optimal fingerprinting approach. The nSWE data are analyzed in preference to SWE because changes in the nSWE are expected to more effectively reflect the impacts of warming on snow storage in nival and mixed nival-pluvial drainage basins such as are found in BC. We reduce the effects of the internal climate variability in the observed diagnostic by averaging the nSWE changes over each spatial domain and over time intervals of $5 \mathrm{yr}$.

The analyses show that the SWE $\mathrm{Epril}_{\text {_1st }}$ has declined over British Columbia consistent with simulations that include responses to the anthropogenic-forcing factors, and consistent with the expected influence of warming on the hydrological cycle. Warming is substantial in the basins that are studied and is also found to be attributable to anthropogenic forcing. We also find that the responses to the natural forcing alone do not explain the observed SWE changes. The D\&A results are found to be robust to the choice of the observed dataset as well as to the removal of the PDO influence. The amplitude of simulated responses are consistent with changes observed in VIC-reconstructed nSWE but are smaller than changes seen in nSWE calculated from manual snow survey records, which represent observations at specific sites rather than grid-cell averages. These analyses combined with previous findings over the western United States (Barnett et al. 2008; Pierce et al. 2008) suggest that human influence has altered both energy- and water-limited regions of western North America.

Although by using a moderately large suite of GCM simulations we considered the uncertainties in the climate model simulations, there are other sources of uncertainties such as the hydrologic model structure and parameterization that should be assessed in future research. Based on the OF approach, it is assumed that the responses to different forcing signals are additive. This assumption has been justified for the study of global temperature changes (Gillett et al. 2004), and given that the NAT responses are close to zero in this study we believe this is a reasonable assumption. In addition Barnett et al. (2008) showed that the signal strengths are influenced by the choice of downscaling methods, although their overall attribution results did not change. Assessing the uncertainties due to different downscaling methods as well as hydrologic model structure can further affirm these findings. Hydrologic models also need driving wind speed and radiation data, in addition to downscaled temperature and precipitation. Consistent with many other studies, wind speed was estimated based on the NCEP-NCAR reanalysis and humidity and radiation were generated using the Mountain Microclimate Simulation Model (MTCLIM) and Tennessee Valley Authority algorithms (Liang et al. 1996; Bohn et al. 2013). In areas where sufficient observations are available to bias correct and disaggregate these variables, it would be desirable to use GCM simulations instead. Finally, the application of optimal fingerprinting in smaller regions is challenging and 
poses difficulty to assess uncertainties. There is less opportunity to increase signal-to-noise ratios in small regions through spatial averaging and less opportunity to avoid multicollinearity between signals by taking advantage of differences in the evolution of the spatial pattern of response for different forcing agents. There is also a greater possibility that the regional responses to external forcing may be confounded with model biases in response patterns that are time and climate-state dependent.

Our analyses were conducted over the period of 19612005 considering the limitations with the available gridded observations and the historical simulations. Recent manual snow survey records and a newly generated observed gridded dataset (A. Cannon et al. 2017, unpublished manuscript) show that nSWE has increased over the period of 2006-12 at a rate of 0.02, 0.01, 0.02, and 0.04 per year in the Fraser, Peace, Columbia, and Campbell River basins, respectively. These seven years fall within the global warming slowdown (hiatus) period (Fyfe et al. 2016). Considering the record-breaking global temperatures observed in 2015 and 2016, which suggests a possible end to the hiatus period, future studies are required to evaluate the most recent changes in the hydrology of western North America.

Acknowledgments. We thank Sanjiv Kumar, Alex Cannon, Markus Schnorbus, Arelia Werner, Rajesh Shrestha, and Drew Snauffer for their help with the snow data and VIC setup. We also thank Xuebin Zhang, Chris Derksen, the editor, and two anonymous referees for their helpful comments. Funding for this project was provided by the Canadian Sea Ice and Snow Evolution (CanSISE) project (Grant RGPCC-433874-2012).

\section{REFERENCES}

Allen, M., and P. Stott, 2003: Estimating signal amplitudes in optimal fingerprinting, Part I: Theory. Climate Dyn., 21, 477-491, doi:10.1007/s00382-003-0313-9.

Arora, V. K., and G. J. Boer, 2001: Effects of simulated climate change on the hydrology of major river basins. J. Geophys. Res., 106, 3335-3348, doi:10.1029/2000JD900620.

Balan Sarojini, B., P. A. Stott, E. Black, and D. Polson, 2012: Fingerprints of changes in annual and seasonal precipitation from CMIP5 models over land and ocean. Geophys. Res. Lett., 39, L21706, doi:10.1029/2012GL053373.

Barnett, T. P., J. C. Adam, and D. P. Lettenmaier, 2005: Potential impacts of a warming climate on water availability in snowdominated regions. Nature, 438, 303-309, doi:10.1038/ nature04141.

— drology of the western United States. Science, 319, 1080-1083, doi:10.1126/science. 1152538 .

Bindoff, N., and Coauthors, 2013: Detection and attribution of climate change: From global to regional. Climate Change 2013:
The Physical Science Basis, T. F. Stocker et al., Eds., Cambridge University Press, 867-952.

Bohn, T. J., B. Livneh, J. W. Oyler, S. W. Running, B. Nijssen, and D. P. Lettenmaier, 2013: Global evaluation of MTCLIM and related algorithms for forcing of ecological and hydrological models. Agric. For. Meteor., 176, 38-49, doi:10.1016/ j.agrformet.2013.03.003.

Cherkauer, K. A., L. C. Bowling, and D. P. Lettenmaier, 2003: Variable infiltration capacity cold land process model updates. Global Planet. Change, 38, 151-159, doi:10.1016/ S0921-8181(03)00025-0.

Das, T., and Coauthors, 2009: Structure and detectability of trends in hydrological measures over the western United States. J. Hydrometeor., 10, 871-892, doi:10.1175/ 2009JHM1095.1.

Déry, S. J., K. Stahl, R. Moore, P. Whitfield, B. Menounos, and J. E. Burford, 2009: Detection of runoff timing changes in pluvial, nival, and glacial rivers of western Canada. Water Resour. Res., 45, W04426, doi:10.1029/2008WR006975.

Diaz, H. F., Ed., 2003: Climate Variability and Change in High Elevation Regions: Past, Present and Future. Springer, 283 pp.

Douville, H., A. Ribes, B. Decharme, R. Alkama, and J. Sheffield, 2013: Anthropogenic influence on multidecadal changes in reconstructed global evapotranspiration. Nat. Climate Change, 3, 59-62, doi:10.1038/nclimate1632.

Fyfe, J., N. Gillett, and G. Marshall, 2012: Human influence on extratropical Southern Hemisphere summer precipitation. Geophys. Res. Lett., 39, L23711, doi:10.1029/2012GL054199.

— , and Coauthors, 2016: Making sense of the early-2000s warming slowdown. Nat. Climate Change, 6, 224-228, doi:10.1038/nclimate2938.

Gillett, N., M. Wehner, S. Tett, and A. Weaver, 2004: Testing the linearity of the response to combined greenhouse gas and sulfate aerosol forcing. Geophys. Res. Lett., 31, L14201, doi:10.1029/2004GL020111.

Groisman, P. Ya., T. R. Karl, R. W. Knight, and G. L. Stenchikov, 1994: Changes of snow cover, temperature, and radiative heat balance over the Northern Hemisphere. J. Climate, 7, 1633-1656, doi:10.1175/1520-0442(1994)007<1633: COSCTA $>2.0 . \mathrm{CO} ; 2$.

—, R. W. Knight, T. R. Karl, D. R. Easterling, B. Sun, and J. H. Lawrimore, 2004: Contemporary changes of the hydrological cycle over the contiguous United States: Trends derived from in situ observations. J. Hydrometeor., 5, 64-85, doi:10.1175/ 1525-7541(2004)005<0064:CCOTHC $>2.0 . \mathrm{CO} ; 2$.

Hamlet, A. F., and D. P. Lettenmaier, 2005: Production of temporally consistent gridded precipitation and temperature fields for the continental United States. J. Hydrometeor., 6, 330-336, doi:10.1175/JHM420.1.

Hasselmann, K., 1997: Multi-pattern fingerprint method for detection and attribution of climate change. Climate Dyn., $\mathbf{1 3}$ 601-611, doi:10.1007/s003820050185.

Hegerl, G. C., T. J. Crowley, M. Allen, W. T. Hyde, H. N. Pollack, J. Smerdon, and E. Zorita, 2007: Detection of human influence on a new, validated 1500-year temperature reconstruction. J. Climate, 20, 650-666, doi:10.1175/JCLI4011.1.

Helsel, D. R., and R. M. Hirsch, 1992: Statistical Methods in Water Resources. Vol. 49, Studies in Environmental Science Series, Elsevier, 522 pp.

Hernández-Henríquez, M. A., S. J. Déry, and C. Derksen, 2015: Polar amplification and elevation-dependence in trends of Northern Hemisphere snow cover extent, 1971-2014. Environ. Res. Lett., 10, 044010, doi:10.1088/1748-9326/10/4/044010. 
Hidalgo, H. G., and Coauthors, 2009: Detection and attribution of streamflow timing changes to climate change in the western United States. J. Climate, 22, 3838-3855, doi:10.1175/ 2009JCLI2470.1.

Jones, G. S., P. A. Stott, and N. Christidis, 2013: Attribution of observed historical near-surface temperature variations to anthropogenic and natural causes using CMIP5 simulations. J. Geophys. Res. Atmos., 118, 4001-4024, doi:10.1002/ jgrd.50239.

Kalnay, E., and Coauthors, 1996: The NCEP/NCAR 40-Year Reanalysis Project. Bull. Amer. Meteor. Soc., 77, 437-471, doi:10.1175/1520-0477(1996)077<0437:TNYRP>2.0.CO;2.

Kang, D. H., X. Shi, H. Gao, and S. J. Déry, 2014: On the changing contribution of snow to the hydrology of the Fraser River Basin, Canada. J. Hydrometeor., 15, 1344-1365, doi:10.1175/ JHM-D-13-0120.1.

—, H. Gao, X. Shi, S. ul Islam, and S. J. Déry, 2016: Impacts of a rapidly declining mountain snowpack on streamflow timing in Canada's Fraser River basin. Sci. Rep., 6, 19299, doi:10.1038/ srep19299.

Knutson, T. R., F. Zeng, and A. T. Wittenberg, 2013: Multimodel assessment of regional surface temperature trends: CMIP3 and CMIP5 twentieth-century simulations. J. Climate, 26, 8709-8743, doi:10.1175/JCLI-D-12-00567.1.

Kumar, S., R. P. Allan, F. Zwiers, D. M. Lawrence, and P. A Dirmeyer, 2015: Revisiting trends in wetness and dryness in the presence of internal climate variability and water limitations over land. Geophys. Res. Lett., 42, 10867-10875, doi:10.1002/2015GL066858.

Liang, X., D. P. Lettenmaier, E. F. Wood, and S. J. Burges, 1994: A simple hydrologically based model of land surface water and energy fluxes for general circulation models. J. Geophys. Res, 99, 14 415-14 415, doi:10.1029/94JD00483.

— - E. F. Wood, and D. P. Lettenmaier, 1996: Surface soil moisture parameterization of the VIC-2L model: Evaluation and modification. Global Planet. Change, 13, 195-206, doi:10.1016/0921-8181(95)00046-1.

Marvel, K., and C. Bonfils, 2013: Identifying external influences on global precipitation. Proc. Natl. Acad. Sci. USA, 110, 1930119306, doi:10.1073/pnas.1314382110.

Maurer, E. P., and H. G. Hidalgo, 2008: Utility of daily vs. monthly large-scale climate data: An intercomparison of two statistical downscaling methods. Hydrol. Earth Syst. Sci., 12, 551-563, doi:10.5194/hess-12-551-2008.

_ _ A. Wood, J. Adam, D. Lettenmaier, and B. Nijssen, 2002: A long-term hydrologically based dataset of land surface fluxes and states for the conterminous United States. J. Climate, 15, 3237-3251, doi:10.1175/1520-0442(2002)015<3237 ALTHBD $>2.0 . C O ; 2$.

Meehl, G. A., C. Covey, T. Delworth, M. Latif, B. McAvaney, J. Mitchell, R. Stouffer, and K. Taylor, 2007: The WCRP CMIP3 multi-model dataset: A new era in climate change research. Bull. Amer. Meteor. Soc., 88, 1383-1394, doi:10.1175/ BAMS-88-9-1383.

Merritt, W. S., Y. Alila, M. Barton, B. Taylor, S. Cohen, and D. Neilsen, 2006: Hydrologic response to scenarios of climate change in sub watersheds of the Okanagan basin, British Columbia. J. Hydrol., 326, 79-108, doi:10.1016/j.jhydrol.2005.10.025

Min, S.-K., X. Zhang, and F. Zwiers, 2008: Human-induced Arctic moistening. Science, 320, 518-520, doi:10.1126/ science. 1153468 .

Mitchell, J., D. Karoly, G. Hegerl, F. Zwiers, M. Allen, and J. Marengo, 2001: Detection of climate change and attribution of causes. Climate Change 2001: The Scientific Basis, J. T. Houghton et al., Eds., Cambridge University Press, 695-738.

Monteith, J., 1965: Evaporation and environment. Symp. Soc. Exp. Biol., 19, 205-234.

Moore, R., and I. McKendry, 1996: Spring snowpack anomaly patterns and winter climatic variability, British Columbia, Canada. Water Resour. Res., 32, 623-632, doi:10.1029/ 95WR03640.

Mote, P. W., 2003: Trends in snow water equivalent in the Pacific Northwest and their climatic causes. Geophys. Res. Lett., 30, 1601, doi:10.1029/2003GL017258.

— A. F. Hamlet, M. P. Clark, and D. P. Lettenmaier, 2005: Declining mountain snowpack in western North America. Bull. Amer. Meteor. Soc., 86, 39-49, doi:10.1175/BAMS-86-1-39.

Najafi, M. R., and H. Moradkhani, 2014: A hierarchical Bayesian approach for the analysis of climate change impact on runoff extremes. Hydrol. Processes, 28, 6292-6308, doi:10.1002/hyp.10113. , and - 2015: Multi-model ensemble analysis of runoff extremes for climate change impact assessments. J. Hydrol., 525, 352-361, doi:10.1016/j.jhydrol.2015.03.045.

, and S. Moazami, 2016: Trends in total precipitation and magnitude-frequency of extreme precipitation in Iran, 19692009. Int. J. Climatol., 36, 1863-1872, doi:10.1002/joc.4465.

- F. W. Zwiers, and N. Gillett, 2015: Attribution of Arctic temperature change to greenhouse-gas and aerosol influences. Nat. Climate Change, 5, 246-249, doi:10.1038/ nclimate2524.

,-- , and -2016 : Attribution of the spring snow cover extent decline in Northern Hemisphere, Eurasia and North America to anthropogenic influence. Climatic Change, 136, 571-586, doi:10.1007/s10584-016-1632-2.

Pederson, G. T., and Coauthors, 2011: The unusual nature of recent snowpack declines in the North American cordillera. Science, 333, 332-335, doi:10.1126/science. 1201570.

Pierce, D. W., and Coauthors, 2008: Attribution of declining western U.S. snowpack to human effects. J. Climate, 21, 64256444, doi:10.1175/2008JCLI2405.1.

Ribes, A., and L. Terray, 2013: Application of regularised optimal fingerprinting to attribution. Part II: Application to global near-surface temperature. Climate Dyn., 41, 2837-2853, doi:10.1007/s00382-013-1736-6.

_ - S. Planton, and L. Terray, 2013: Application of regularised optimal fingerprinting to attribution. Part I: Method, properties and idealised analysis. Climate Dyn., 41, 2817-2836, doi:10.1007/s00382-013-1735-7.

Rupp, D. E., P. W. Mote, N. L. Bindoff, P. A. Stott, and D. A. Robinson, 2013: Detection and attribution of observed changes in Northern Hemisphere spring snow cover. J. Climate, 26, 6904-6914, doi:10.1175/JCLI-D-12-00563.1.

Santer, B. D., and Coauthors, 2007: Identification of human-induced changes in atmospheric moisture content. Proc. Natl. Acad. Sci. USA, 104, 15 248-15 253, doi:10.1073/pnas.0702872104.

Schnorbus, M., A. Werner, and K. Bennett, 2010: Quantifying the water resource impacts of mountain pine beetle and associated salvage harvest operations across a range of watershed scales: Hydrologic modeling of the Fraser River Basin. Natural Resources Canada, Pacific Forestry Centre, Rep. BC-X-423, 64 pp. [Available online at https://cfs.nrcan.gc.ca/publications? $\mathrm{id}=31207$.

, K. Bennett, A. Werner, and A. Berland, 2011: Hydrologic impacts of climate change in the Peace, Campbell and Columbia watersheds, British Columbia, Canada. Pacific Climate Impacts Consortium, University of Victoria, $157 \mathrm{pp}$. 
A. Werner, and K. Bennett, 2014: Impacts of climate change in three hydrologic regimes in British Columbia, Canada. Hydrol. Process., 28, 1170-1189, doi:10.1002/hyp.9661.

Sen, P. K., 1968: Estimates of the regression coefficient based on Kendall's tau. J. Amer. Stat. Assoc., 63, 1379-1389, doi:10.1080/ 01621459.1968.10480934.

Shrestha, R. R., M. A. Schnorbus, A. T. Werner, and A. J. Berland, 2012: Modelling spatial and temporal variability of hydrologic impacts of climate change in the Fraser River basin, British Columbia, Canada. Hydrol. Processes, 26, 1840-1860, doi:10.1002/ hyp. 9283.

Stott, P. A., N. P. Gillett, G. C. Hegerl, D. J. Karoly, D. A. Stone, X. Zhang, and F. Zwiers, 2010: Detection and attribution of climate change: A regional perspective. Wiley Interdiscip. Rev.: Climate Change, 1, 192-211, doi:10.1002/wcc.34.

Taylor, K. E., R. J. Stouffer, and G. A. Meehl, 2012: An overview of CMIP5 and the experiment design. Bull. Amer. Meteor. Soc., 93, 485-498, doi:10.1175/BAMS-D-11-00094.1.

Vaughan, D. G., and Coauthors, 2013: Observations: Cryosphere. Climate Change 2013: The Physical Science Basis, T. F. Stocker et al., Eds., Cambridge University Press, 317-382.
Vincent, L., X. Zhang, R. Brown, Y. Feng, E. Mekis, E. Milewska, H. Wan, and X. Wang, 2015: Observed trends in Canada's climate and influence of low-frequency variability modes. J. Climate, 28, 4545-4560, doi:10.1175/ JCLI-D-14-00697.1.

Wood, A. W., E. P. Maurer, A. Kumar, and D. P. Lettenmaier, 2002: Long-range experimental hydrologic forecasting for the eastern United States. J. Geophys. Res., 107, 4429, doi:10.1029/ 2001JD000659.

Zhang, X., L. A. Vincent, W. Hogg, and A. Niitsoo, 2000: Temperature and precipitation trends in Canada during the 20th century. Atmos.-Ocean, 38, 395-429, doi:10.1080/ 07055900.2000 .9649654$.

— , F. W. Zwiers, G. C. Hegerl, F. H. Lambert, N. P. Gillett, S. Solomon, P. A. Stott, and T. Nozawa, 2007: Detection of human influence on twentieth-century precipitation trends. Nature, 448, 461-465, doi:10.1038/nature06025.

Zwiers, F. W., G. C. Hegerl, X. Zhang, and Q. Wen, 2014: Quantifying the human and natural contributions to observed climate change. Statistics in Action: A Canadian Outlook, J. Lawless, Ed., CRC-Chapman, 321-340. 